\title{
Ecological architecture as a forgotten opportunity in Vietnam
}

\author{
Thanh Son Le $\mathrm{Le}^{1, *}$ \\ ${ }^{1}$ University of Architecture HCMC (UAH), 196 Pasteur Str., Ward 06, District 3, Ho Chi Minh City, \\ Vietnam
}

\begin{abstract}
Ecological Architecture is a modern topic. In Viet Nam, this topic attracted a great attention, and eventually, it is considered as a new trend, both theoretical and practical. This article presents different perspectives, but not the common public opinions on the issue, in particular, as follows: comparison of the relationship between the traditional Vietnamese architecture and the modern ecological architecture to acknowledge the similarity rather than the difference; the lessons learned from a particular stage of development in Vietnam before 1975 as an empirical result for modern ecological and environmental theories; discussion of the missed opportunity for the integration and contribution of modern Vietnamese architecture in terms of both theoretical and ecological development of Vietnamese architecture in the context of globalization.
\end{abstract}

\section{Introduction}

In the bond with the Nature, Westerners has a different approach from the East's. Whenever there was a "crisis" of/with Nature, Westerners often conducted sophisticated scientific researches to seek solutions. In the other words, they came to "Mother Nature" - a scientific object - to "consult". In the same situation, Easterners often seek answers from the "ancestors" - or, more precisely, from traditional experiences and solutions. "Mother Nature" and "The experience of the ancestors" are objects that able to give various approaches to the same problems solutions. However, the results of these solutions, are not the same, and so their implications, if happened, are different.

\section{Literature review}

It is interesting to acknowledge that, the French architects, headed by Hébrard, were pioneers in studying the values of traditional culture, transforming and applying them, to improve the quality of modern architecture in Vietnam. Between 1923 and 1942, the French architects realized that it was impossible to impose all the European architecture into Indochina. After much debate, they finally made some adjustments and changes, some visionary architects had come to realize that the native architectural environment inherits many legacies unique culture that they had not previously been able to penetrate and study. Hébrard, Chief

\footnotetext{
* Corresponding author: son.lethanh@uah.edu.vn
} 
Architect of the Construction Inspectorator of the Indochina in 1923, publicly criticized the way in which the urban landscape was viewed and worsened: "We need to protect our houses against the solar radiation, against the storms. We need to make the city look suitable for hot and humid climate. There should be shelters in the commercial ground". He also proposed a new architectural design that suitable for indigenous climatic conditions, known as Indochinese Style Architecture [5, 7].

After 1940, the first generation of Vietnamese architects educated by the French showed a spirit oriented to studying the experiences of traditional construction and the results were also look promising. That is making of architectural solutions suitable for tropical climate in Vietnam. The architecture of this first generation of architects shows that many elements of traditional architecture are in great harmony with modern architecture. These are large verandas, roofs, ventilation holes on the walls, decorative motifs .... It can be said that these two evidences, the French architects and the first generation of Vietnamese architects, are the first steps of modern architecture working on the ability to apply the lessons of the ancestors to achieve the effect of local climate conditions. Today's ecological architecture has the same goals [5].

Technically, Vuong Quoc My's thesis: "The influence of climate on urban housing formation in North Vietnam" (1962), "Climate and Housing" (1966) and the book"Architecture thermology" (1966) of Pham Ngoc Dang were the earliest scientific study in Vietnam on climate-friendly architecture. They were followed by some publications by Hoang Huy Thang, Nguyen Huy Con, Pham Duc Nguyen, ect. Which were also the studies of the effects of climate factors on architecture [4]. In general, the approach of doing research is to apply the knowledge of science to the design calculus without astonishment, which draws from the traditional building experience in Vietnam as a visual lesson. There were the points of view and the approaches that locate traditional building experiences in Vietnam in a much lower position than those of Western experimental science. To put it more precisely, traditional building experiences have been forgotten.

Books about Vietnamese architecture in general, in terms of traditional architecture in particular, is not of great quantity. Especially lack of depth studies of lessons from traditional architecture. For example, The book "The history of Vietnamese architecture" (1996) by Ngo Huy Quynh - a first-generation architect of Vietnam - is a study of general history, so the experience of traditional architecture is not the main subject. Be treated badly, the forgotten of lessons from traditional culture and architecture, are predictable [5].

\section{Materials and methods}

In the spirit of "ôn cố nhi tri tân" (analysis the old to make something new), we think that it is necessary to acknowledge the whole treasure of folklore cultural experiences to define a new approach. It is because in Vietnam, folklore culture is the strongest, richest and most receptive. The clarification of the relationship between the solutions of traditional Vietnamese architecture and the solutions of ecological architecture - which is being transmitted extensively on present architectural presentations - is meaningful.

To reinforce the approaches, the evidence of the lessons learned in the years before 1975 shows that the development of ecological architecture in Vietnam is a reality.

The methods used in this study are very common in scientific research, but also very useful.

- The Historic Method offers great effects. This method helps to explore, select various lessons from the rich cultural life of the Vietnamese people, their experience in dealing with the natural environment. 
- Inductive and Deductive Method help to understand the architectural phenomena that have historically been happened and able to infer similar phenomena to recognize the essence of things.

- Diachronic comparison is the most important method used in this study. It provides a holistic view from the lessons learned in the past to the modern solutions of Ecological Architecture. From there it is possible to draw the scientific hypotheses needed to confirm the similarity between the traditional Vietnamese architecture and the current ecological architecture.

- Analysis and Synthesis are the necessary methods, from which to make the appropriate conclusions for the research direction that the article expects.

\section{Results}

This study gave two results:

\subsection{Some similarities between the solutions of traditional Vietnamese architecture and Ecological Architecture}

Direction: Many Vietnamese generations had affirmed the best direction to build a house is the South, there was an idiom: "Lấy vợ đàn bà, làm nhà hướng Nam" (To marry a woman, to build a house at the South). Having the direction of the house South is inevitable. Houses with this direction would have some very practical effects: receiving cool air in the summer and able to protect itself from the cold winds in the winter. Modern Ecological Architecture highlights the same elements in its design. It is advisable to have the auxiliary space (stairs, elevators, warehouses, toilets, corridors, etc.) toward the Westside of the house - the most unfavorable temperature in terms side in Vietnam (Fig 1).

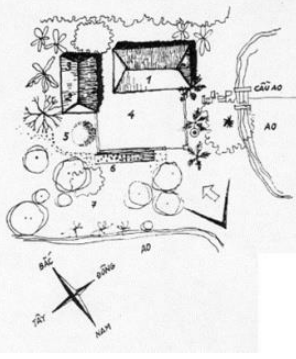

$01 \mathrm{~A}$ - Master plan of traditional house
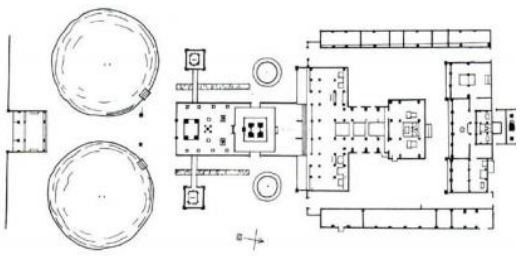

01B-Master plan of Pho Minh Pagoda

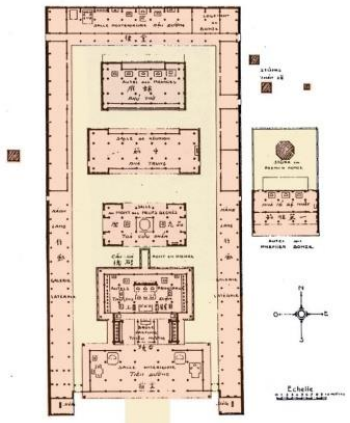

01C -Master plan of Ninh Phuc Pagoda

Fig. 1. The best direction to build a house in Vietnam is the South (Source: [3]).

Carrying a house, Vietnamese people always think about its master plan under the motto: "Trước cau, sau chuối" - "Trước đào ao, sau vực nền" Vietnamese dwellings, from the northern delta to central Vietnam, adhered to this motto. The benefit of "Trước cau, sau chuối" is very practical, in particular: tall and straight arecas will allow cool wind from the water surface blowing into the house, avoiding a low humidity; The banana bushes with the large, low body will prevent the cold wind from the north. The advantage of "Trước đào ao, sau vực nền" (Have a pond in front of the house, have a basement behind it). A frontal pond is both a water supply resource and an aquaculture factor, it also helps to reduce the impact of heavy rains and floods. A frontal pond is also ideal to creating nice landscape and good 
climate for human health. On this point, Ecological Architecture shares the same idea of "Utilizing the natural water" to create a landscape environment. Modern architecture will improve itself a lot if the architect exploits the advantage of water surface elements (Fig 2).

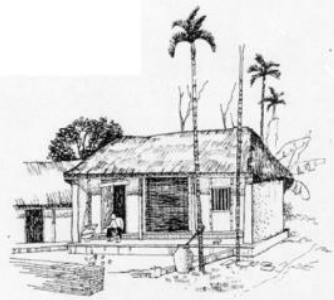

02A - A traditional house built with the motto: "Trước cau, sau chuối"

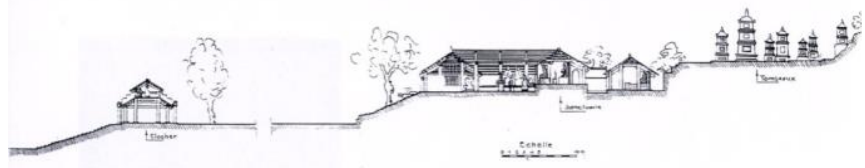

02B- Section of Van Phuc Pagoda - built under the motto:"Trước đào ao, sau vực nền" - Have a pond in front of the house, have a basement behind it

Fig. 2. Two examples of building a house in Vietnam follow the traditional mottoes (Source: [3]).

The typical Vietnamese house layout is usually characterized by the following shapes: Chữ Nhất - Chữ Nhị - Chữ Tam - or Nội Công - ngoại Quốc to circulate and ventilate air easily and directly. Patio and inner courtyard are the buffer zones means to reduce heat radiation, it also facilitating easy and direct air ventilation and create artificial scenes and help to grow a bond with nature. The love for nature eventually has the effect of developing positive personality for human beings.

This coincidence has been modernized in modern architecture on the basis of specific solutions: the arrangement of auxiliary functions, the balcony, the Westside corridor - to create an intermediate space in the side with unfavorable climate. In addition, the purposes to create skylights, gardens on the floor such as The National Library of Singapore (Ken Yeang) is to create a sense of closeness, artificial landscapes, nature love and ventilation air across floors through the whole building (Fig 3).

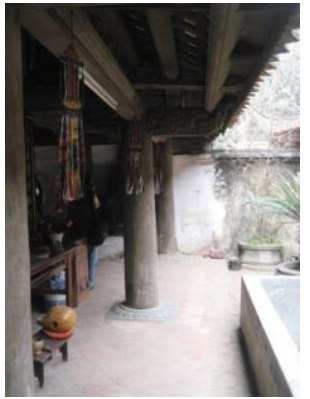

03A - Light well in

Tay Phuong Pagoda (Source: [6])

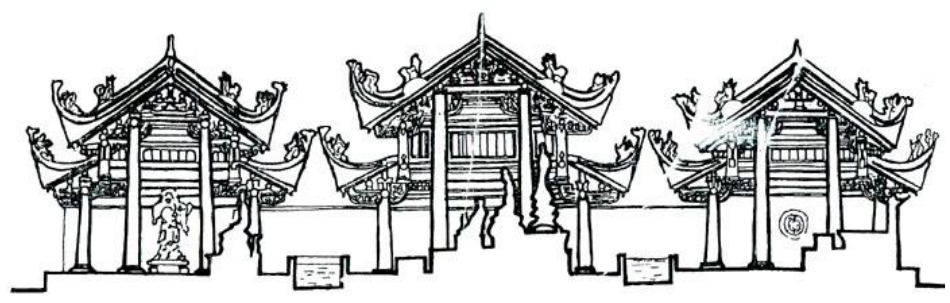

03B- Section of Tay Phuong Pagoda - the shapes: Chr̃ Tam - or Nội Công - ngoại Quốc to circulate and ventilate air easily and directly (Source: [3])

Fig. 3. Typical Vietnamese architecture layout.

Traditional Vietnamese house is a special product of herbal material, in which wood structure is typical with wooden trusses: vỏ cua trusses, chồng rường trusses, giả thủ trusses, xà, trính ... with the sophisticated techniques such as ghép mộng, con xỏ... Especially those are all organic material, can be recycled or decomposed after use. Today's ecological architecture also avoids to abuse the Nature by using organic materials, columnar structures, metal momentum, flooring, etc., which are materials that can be utilized, restore or recycle, thus limiting the introduction of waste into the environment, leading to the risk of environmental destruction. 
Dầm mút thừa (kẻ - bẩy), Đấu-cung in the traditional Vietnamese house is a creation of intermediate spaces between the inside and outside, enhancing the ability to protect the house from the sun and rain. These constructs are equivalent to the console form of modern architecture (Fig 4).

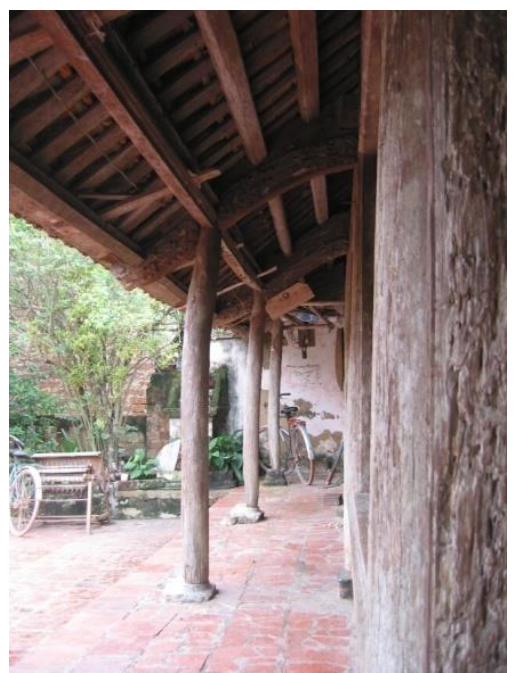

04A - Dầm mút thừa (kẻ - bẩy)- the typical of wood structure in a traditional house is a creation of intermediate spaces between the inside and outside (Source: [6])

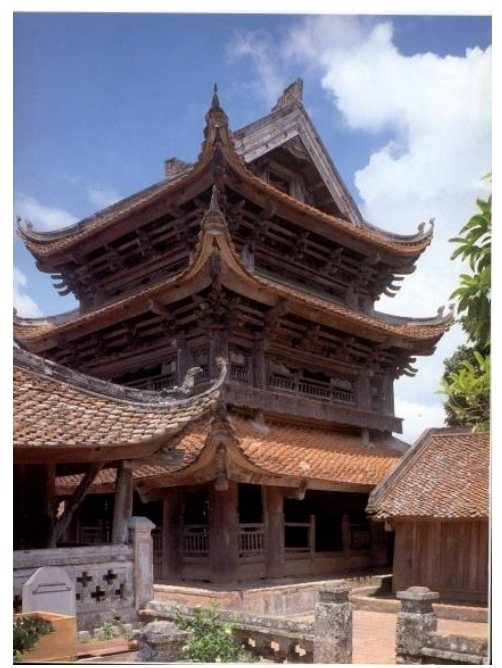

04B - Đấu-cung in the Keo Pagoda enhancing the ability to protect the house from the sun and rain (Source: [6])

Fig. 4. Traditional Vietnamese house - the wood structure is typical with wooden trusses.

The roof is one of the most important components of traditional Vietnamese house. The solutions for roof are also diverse and very rich: mái chồng diêm, khu đĩ in two gables, nhà mái lá, mái hai lớp (2-layer leaves roofs) in the Central of Vietnam... is to insulate and convect air in the roof, along with the system of mái hắt, giàn leo... to cover from the sun, bringing the beauty of nature into the house. Commonly used materials are: wood, bamboo, mud, tile, various type of straw, Âm dương tile...(Fig 5)

Ecological Architecture today also uses the same solution: mái chồng diêm (2-layer roof), cửa sổ mái (windows roof), mái kép (double roofs), lawns, pool on the roof, auvent, pergola... Name, materials and compositional techniques can be different, but the purpose is the same.
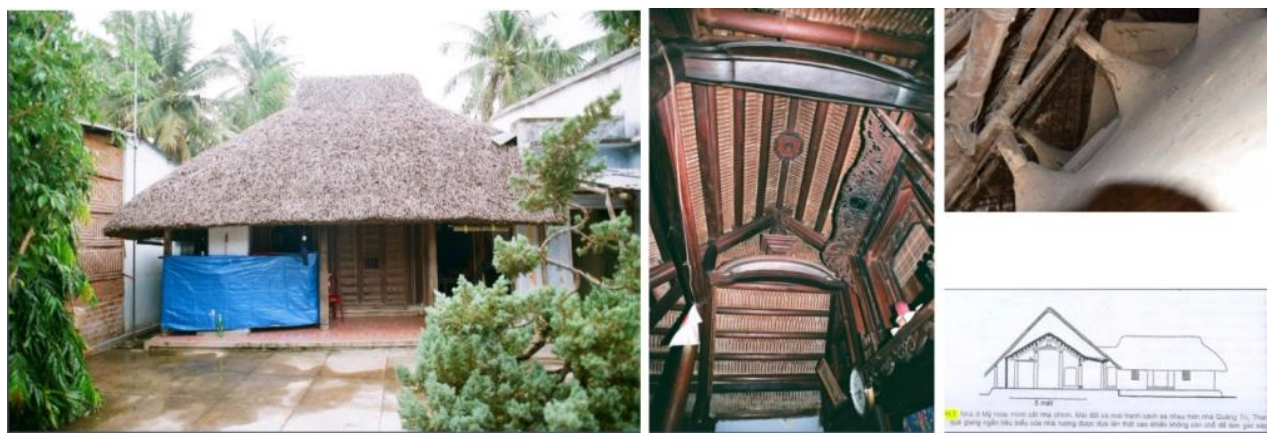

Fig. 5. Nhà mái lá, mái hai lớp (2-layer leaves roofs) in the Central of Vietnam (Source: [1]).

The covering texture of the traditional Vietnamese home is varied, rich in materials and categories: tường trinh (mud - straw walls), tường gạch phơi khô (dry brick walls) with 
organic mortar joints. Doors: cửa bức bàn, song cửa, phên, giại, tường hoa...... with the effect of preventing heat penetration into the house during the summer, and keep the inside warm in winter, allow air convection inside-out (Fig 6).

This technique is now modernized in double-walled solutions, to create air convection between the layers of the house surface. A synthetic sun louver is a layer that prevents heat radiation.

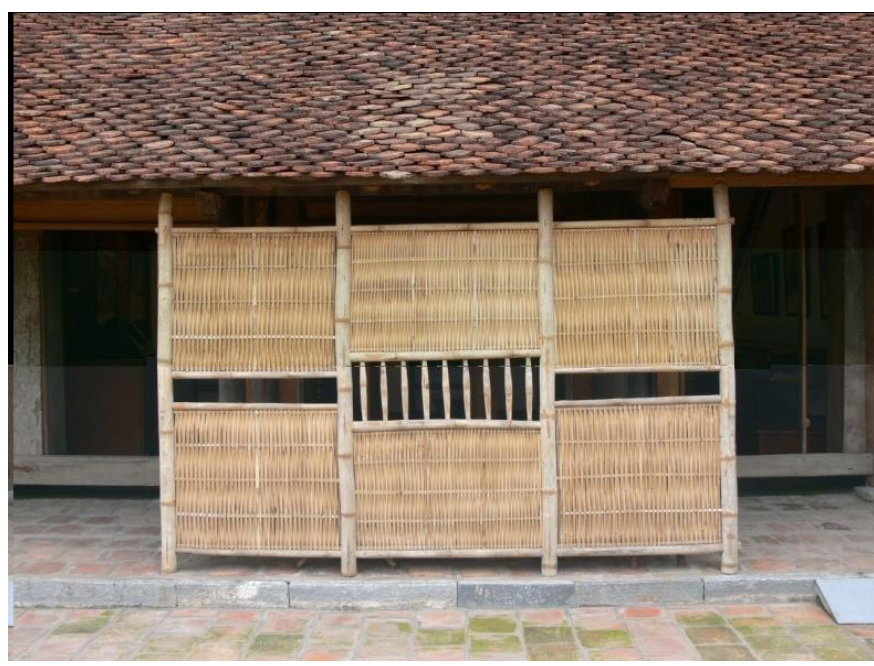

06A - Phên, giại in a traditional house (Source: [6])

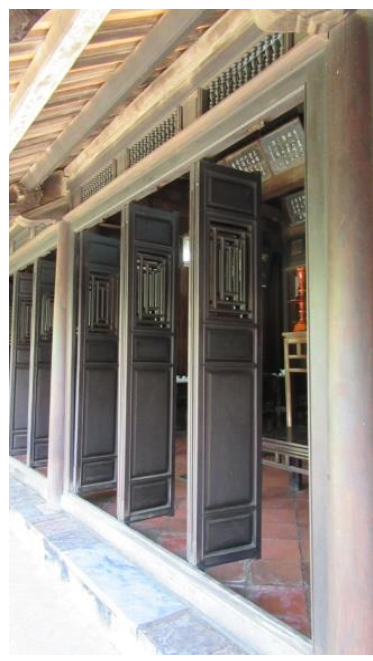

06B - The wooden door "thượng song , hạ bản" in a traditional house (Source:

[6])

Fig. 6. The covering texture of traditional Vietnamese house.

Traditional Vietnamese house uses sàn gỗ ván (wooden floor) as a ground - floor system. The isolation from the ground helps to prevent moisture and air circulation easily (Fig 7).
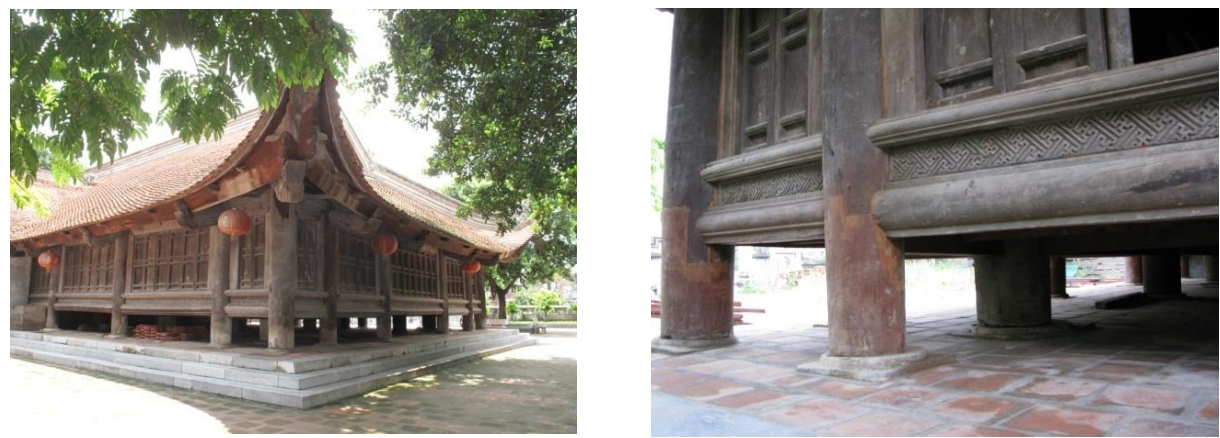

Fig. 7. A wooden flooring system of traditional Vietnamese house (Source: [6]).

The form \& layout commonly found in traditional Vietnamese houses is a chain of spaces: The house - The yard - The well - The garden - The fish pond - The barn ... All formed a natural ecological cycle that sealed into a self-productive method, which can be generalized as a module of: Vườn - Ao - Chuồng ( $\mathrm{V}$ - A - C) (Garden - Pond - Barn). In which the material operates according to the principle that the waste from the process of pre-use becomes the raw material for the following process (Fig 8). 


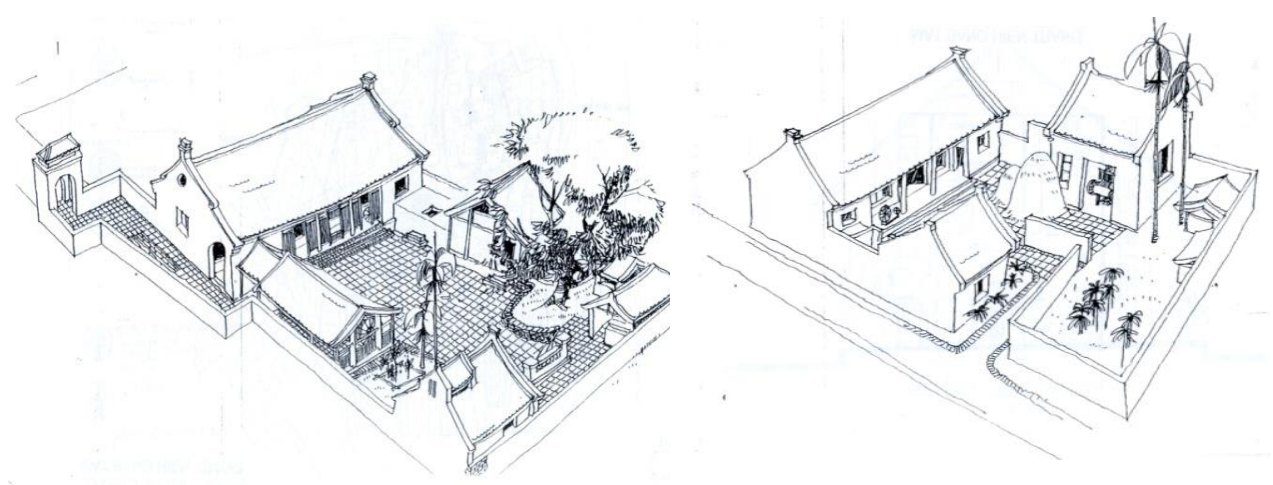

Fig. 8. The commonly form \& layout in traditional Vietnamese houses (Source: [3]).

Energy is an important issue in the architecture. A fine architecture always considers the energy factor.

The brick yard in the traditional Vietnamese house takes on many functions: both as a place of living and as a place to collect sunlight to dry the farm produce. Even hot, smoky kitchens also have the effect of drying farm produce, while straw is the main source of fuel. The barn provides fertilizer for the garden (Fig 9).

Nowadays, advanced technologies such as biogas, wind power \& solar energy are being exploited more and more effectively to minimize the use of reserve fuels.

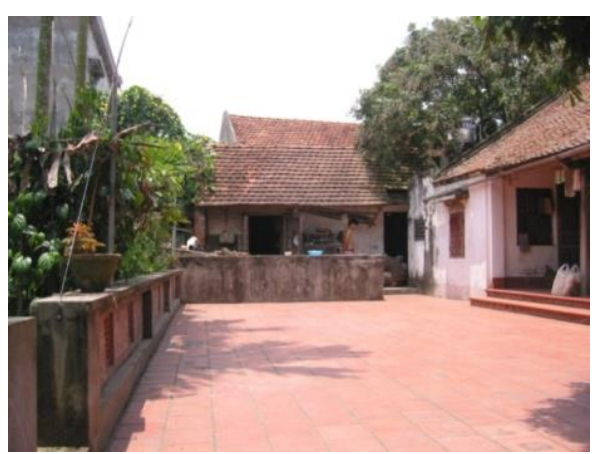

09A - Brick yard - a most important space of a traditional Vietnamese house (Source: [6])

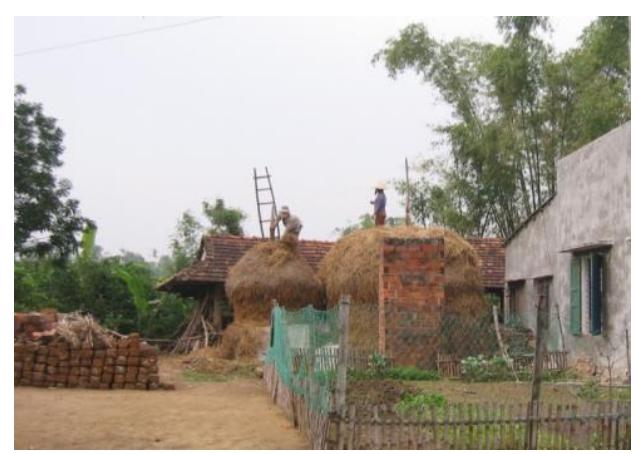

09B - Straw is the main source of fuel in traditional Vietnamese house (Source: [6])

Fig. 9. Energy is an important issue in traditional Vietnamese houses.

Language and image of traditional Vietnamese architecture have built a unique and distinctive visual language. It went into the subconscious of the ethnic community $\&$ became a sustainable value.

We agreed that the image of traditional Vietnamese architecture is not only symbolic, but also ecologically meaningful and would bring positive effects if successfully exploited, a positive effect for the cohesion of the community (Fig 10). 


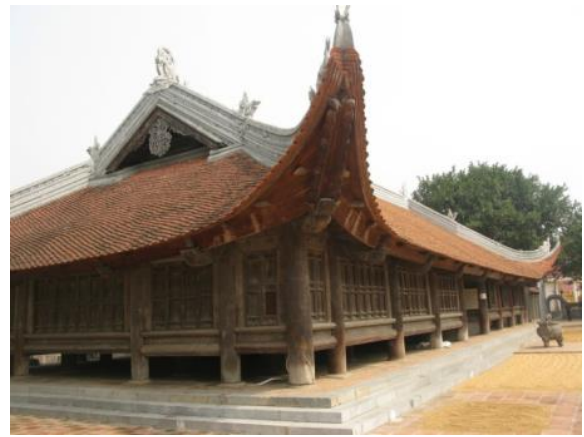

10A -Dinh Bang Village's Dinh - a famous common house in Bắc Ninh province (Source: [6])

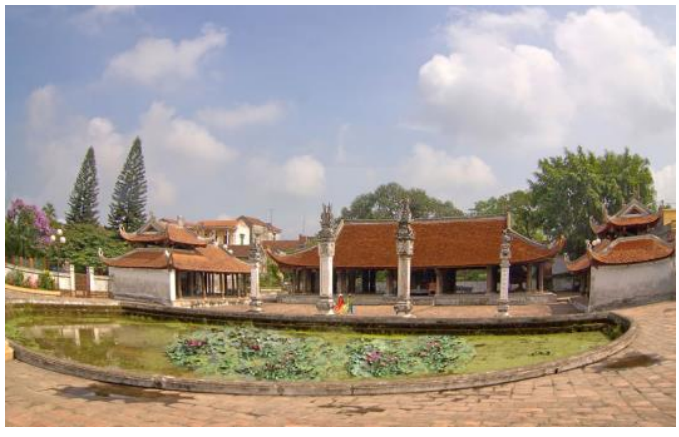

10B-Tay Dang Village's Dinh, Hanoi - A unique and distinctive visual language of traditional Vietnamese architecture (Photo: Nguyen Anh Tuan, 2011)

Fig. 10. Language and image of traditional Vietnamese architecture.

To compare the solutions of traditional Vietnamese architecture with today's Ecological Architecture in all the architectural elements are presented in the section 4.2. The section 4.2. shows the main similarity. From this comparison, the solution to the contemporary problems can come from traditional experience. In the other words, the experience of the ancestors needs to be thoroughly employed, promoted and modernized, instead of "importing" too quickly the technology and products from the foreign industrial corporations.

\subsection{Modernist - Tropicalise Architecture in Vietnam 1960 - 1975}

In this section, we would like to introduce some of the solutions of Modernism in Vietnam in the 1960s - 1975 - also known as Modernist Tropicalise Architecture - has made great efforts and achievements on the criteria and solutions of Ecological Architecture.

One of the most famous of these is the National Library (now the Science Encyclopedia Library of Ho Chi Minh City). Architects Nguyen Huu Thien and Bui Quang Hanh have ingeniously combined the forms of traditional architectural works with modern functions, consistently adapted to the tropical climate. First, the concept of using traditional wooden flooring structure on the water surface has created a familiar look of indigenous architecture and has contributed to reducing the heat of the tropics (micro-climate solutions) (Fig 11) [4].

Although the building uses a lot of reinforced concrete - a modern material at the time but is presented with a new shade. Reinforced concrete structure has been transformed into elements of traditional wooden architecture such as columns, beams, consoles, roofs, corridors, claustra panels ... All as an ensemble to protect the structure. From extra sunshine, rainy weather and also receives the natural breeze from the outside by using rooms ventilation.

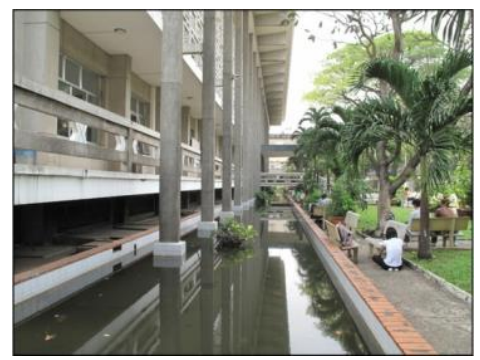

Fig. 11. The National Library (Source: [6]). 
Independence Palace, by architects Ngo Viet Thu is also another famous work of Modernist architecture. The most remarkable is the rèm hoa đá (claustra beton panels) system at the front of the building with elegant shape, rich in East Asia Yin qualities (a unique characteristic of East Asia).The "claustra panels" with reinforced concrete not only blocks the glare of the sun's rays from outside the building, but also forms reflective surfaces so that light can penetrate into the building after its heat has been eliminated. The curtains also blow away the heat left inside the building (Fig 12) [4].
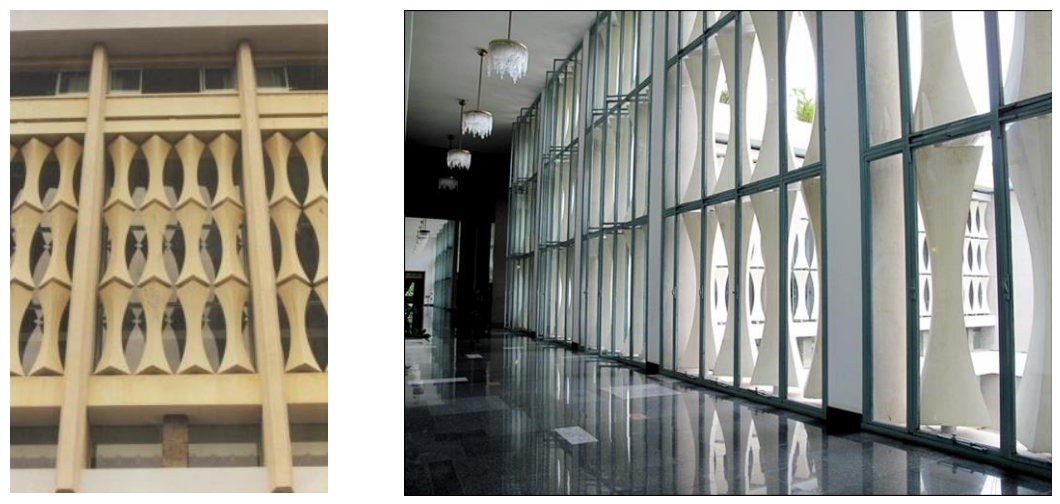

Fig. 12. Independence Palace (Source: [6]).

ESSO Headquarters, by architect Tran Dinh Quyen, located at the corner of Le Duan and Hai Ba Trung expressing the efforts in the advanced direction of architectural physics in tropical climates. The south-east and south-west faces use a vertical system of sun blinds, combined with horizontal panels such as shutter blades to shield from the sun's radiation and rain. However, the north face along Hai Ba Trung Street is completely just a glass door, completely contrasting with the other two sides. This treatment has shown that the effort to adapt to the natural conditions of each side is perfectly suited to both modern and traditional elements (Fig13) [4].

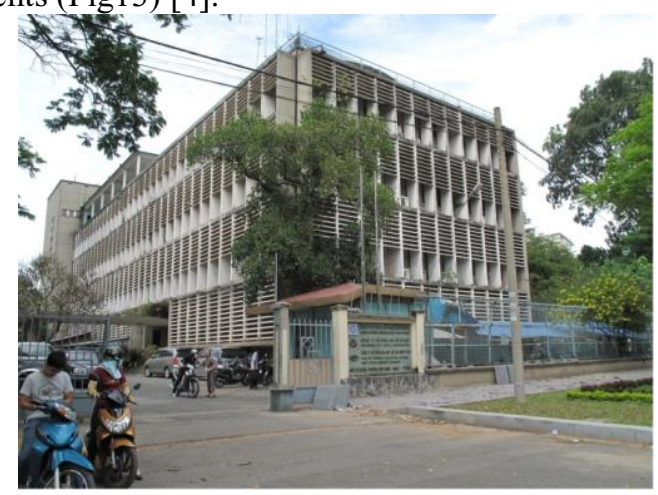

Fig. 13. ESSO Headquarters (Source: [4]).

Viet Nam Commercial Bank, by architect Tran Van Ba, has a four-storey elevated building shielded by an innovatively shaped lamellae system that looks like reinforced concrete "bamboo trunk" create ventilation, against the sultry of the North and West. It can be said that this is the solution of "wall curtain" quite successful in terms of traditional motif of decoration, on the other hand is very effective in responding to tropical climate conditions (Fig14) [4]. 


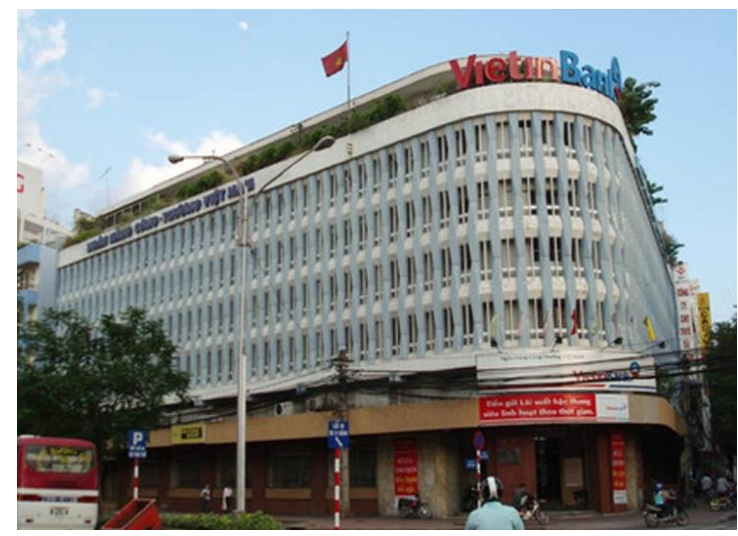

Fig. 14. Viet Nam Commercial Bank (Source: [4]).

Vietnam Commercial Bank (Fig15) and BNP (Banque Nationale de Paris) (Fig16), designed by Nguyen Van Hoa - Pham Van Thang - Nguyen Quang Nhac' studio, with reinforced concrete louver run throughout the height of the building. There are also a large verandas on the ground floor surrounding the entire building. [4]

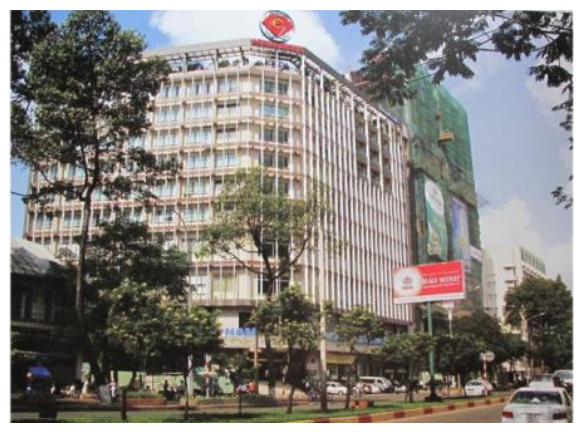

Fig. 15. Vietnam Commercial Bank (Source: [4])

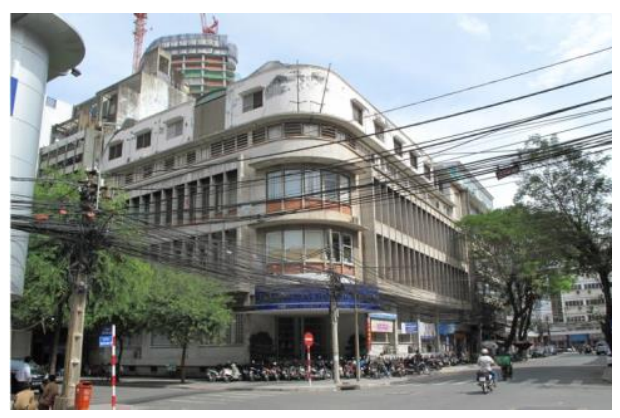

Fig. 16. BNP (Banque Nationale de Paris) (Source: [4]).

Other important building of the Modernist Architecture of Tropicalism include: People's Hospital, Cho Ray Hospital, Sai Gon Medical Education Center, National Center for Agriculture and Forestry, University campus Thu Duc, Can Tho University...

Therefore, the exploitation of forms of traditional architecture of the Modernist Architecture of Vietnam is not merely to solve the requirements of aesthetic or spiritual, but also towards a basic content. More than that, it solves the problem of adaptation to tropical climate, hot and humid. These encouraging results show us that the solutions of traditional architecture have been applied quite effectively. Particularly:

- Claustra beton panels, vertical lamination system, horizontal lamellae, curtain system "reinforced concrete" ... are commonly used by adaptive the benefits of the cửa bức bàn, song cửa, phên, giại, tường hoa... of traditional architecture (Fig 17). 


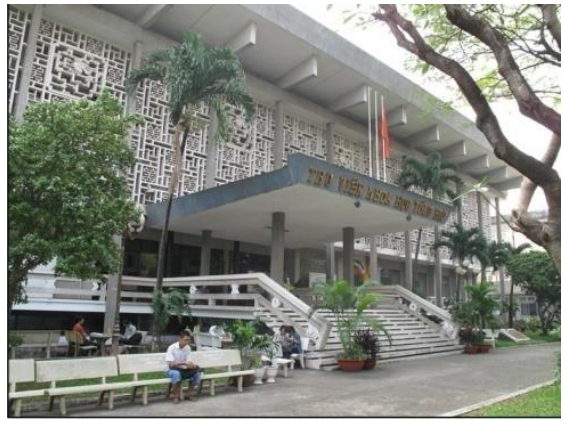

Fig. 17A. The National Library (Source: [6]).

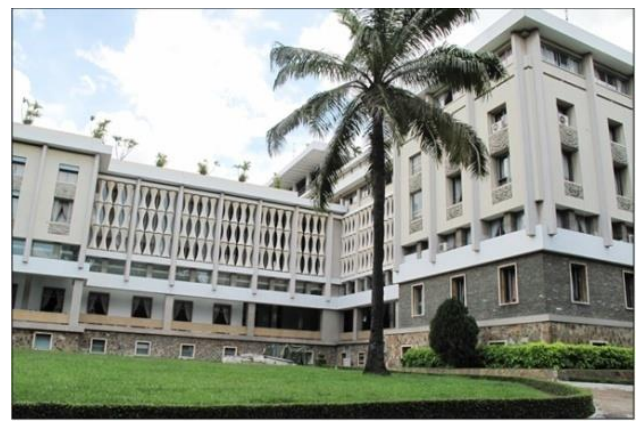

Fig. 17B. Independence Palace (Source: [6]).

- The combination of wall panels, reinforced concrete "curtain" and corridors created a double-skinned wall of Ecological Architecture (Fig 18A, B).

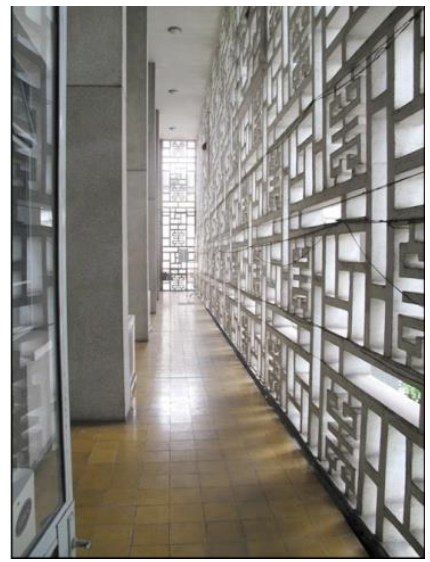

Fig. 18A. The National Library (Source: [6]).

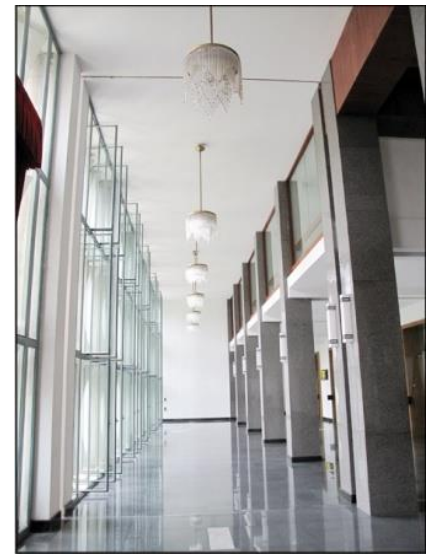

Fig. 18B. Independence Palace (Source: [6]).

- The solution to use natural water, garden roof ... create both beautiful scenery and the solution for micro climate (Fig 19).

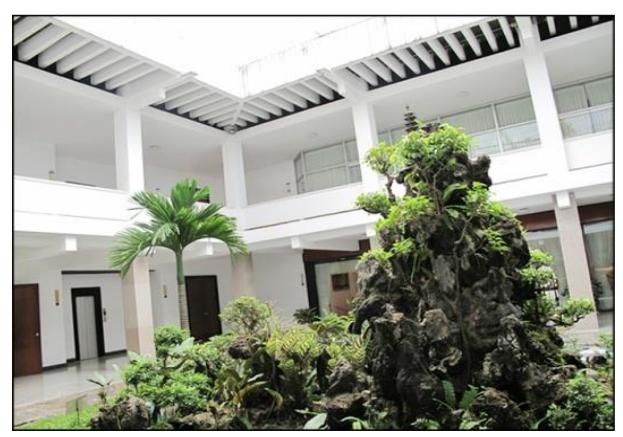

Fig. 19. Independence Palace (Source: [4]).

- The double roof solution in the High School of Engineering and High School, Vinh Long, designed by architects Tran Van Loi, Bui Quang Hanh and Le Van Lam to enhance the insulation and convection in the roof (Fig 20). 


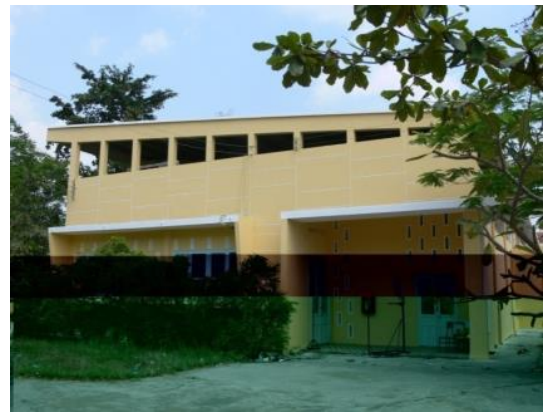

Fig. 20A. Elevation of the Meeting Hall of High School of Engineering and High School, Vinh Long (Source: [4]).

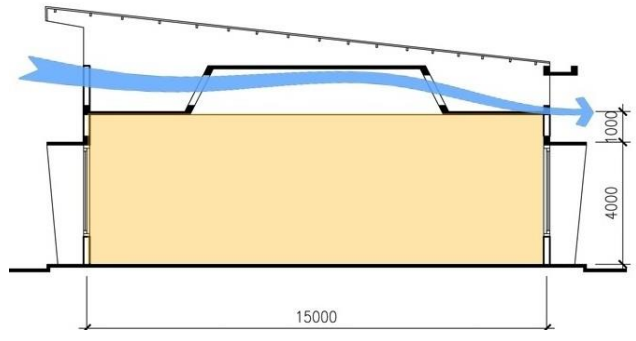

Fig 20B. Section of the Meeting Hall of High School of Engineering and High School, Vinh Long (Source: [4]).

\section{Discussion}

The above analysis is a proof that the precious experience that Vietnamese ancestors have accumulated for thousands of years is quite equivalent to the solutions that Ecology Architecture is promoting. As a matter of common logic, Vietnam may have been one of the initiators, in this field. Therefore, it should be confirmed that Ecological Architecture is not new in theory and practice in Vietnam; Discussing about the possibility of "integration", this is a potential, a strength of modern Vietnamese architecture. In our view, the real problem that contemporary Vietnamese architecture is facing is not really active in exploiting the valuable lessons of traditional culture and architecture. In fact, contemporary Vietnamese architecture exhibits a variety of fashionable, exotic elements instead of a practical spirit.

Today, in the context of globalization, where everywhere in the world, architecture is called towards sustainable development, environmentally friendly, and energy saving, etc. the Vietnamese architecture, in fact, had been early manifestations of the development of ecological architecture.

The preliminary statistics mentioned above have shown a pioneering architectural direction that has been practiced in South Vietnam since 1975. But the most disturbing thing is that if from the moment the promotion and conclusion of the theory on this trend of progressive architecture is conducted in a professional manner, the opportunity to introduce to the international academy about the motto of living and sustainable development, the traditional Vietnamese architecture has not been so "fogy". Perhaps from that time, the world has come to know the notion that today has been modernized in the name of Ecological Architecture. That for Vietnamese architects, Ecological Architecture is not a completely new and unfamiliar concept, but this is an antique, refurbished, modernized concept. Unfortunately, this golden opportunity has been missed due to our short-sighted, slow, sometimes even indifferent, traditional way of thinking, ect.

At present, in the effort to overcome this fogy, if we continue to introduce new technology from foreign countries but not to deepen our study of the precious experiences our ancestors have, it is certain that our new architecture has many more serious implications. We realize that under the danger of the exoticism, a foreign-paternalism of an "exotic ecosystem architecture", our poor country is easy to become harassed, a junk yard of the world. The market for companies of aluminum composite panels, toughened glass, closed circulation cycle chemistry, ect. So, the values of traditional Vietnamese architecture are again at risk of being forgotten as it has been treated in the past. 


\section{Conclusions}

The most important conclusion to draw from the above researches is to recognize properly the reality of globalization and specific conditions of Vietnam in order to have appropriate solutions for the development of Vietnamese architecture as an inclusive, equitable and contemporary world-class architecture, both theoretical as well as practical. Globalization and integration are inevitable, but a country with weak economic potential must choose a smarter, less noisy approach to avoid the dangers of massively unproven importing technology that we have not yet qualified to control and master it. In our opinion, after the overwhelming publicity that comes from companies offering new products and construction technologies under the name of Ecological Architecture, perseverance approaches traditional culture and architecture, with the experience of ancestors, the principles of architectural design are always the approach that is suitable for contemporary Vietnamese architecture.

\section{References}

1. T. Nguyễn, Two-layer leaves roofs in the Central- ecological architecture, Journal of Planning and Urban Development in Vietnam (2011)

2. T. L. Vũ, Vietnamese History of Architecture (Construction Publish House, Hanoi, 2012)

3. T. T. Ngô, Possibility of Tropicalise in Vietnamese Modern Architecture - Stage 1954 1975. Master Thesis (Library of University of Architecture HCMC (UAH), 2010)

4. T. S. Lê, The Phenomenon of Cultural Symbiosis between Traditionality and Modernity in Vietnamese Architecture from the Late Nineteenth Century to the Middle of the Twentieth Century, Doctoral Thesis (Library of Library of University of Architecture HCMC (UAH), 2010)

5. T. S. Lê, Ecological Concept in Vietnamese House. VIETARC'09 International Architecture Forum "Architecture in VN: Meeting the Challenges of Tomorrow" (2009)

6. H. T. Nguyễn, Outstanding architects of Saigon before 1975 (2016) http://tuoitre.vn/tin/chinh-tri-xa-hoi/phong-su-ky-su/20160824/nhung-kts-tai-danh-cuasai-gon-truoc-1975/1159918.html

7. D. T. Nguyễn, Doctoral Thesis (Library of Hanoi University of Architecture, 1998) 